\title{
Management of Personnel Potential in Higher School in the Conditions of the Organizational Changes and the Transition to a Digital Economy
}

\author{
Irina Pavlova \\ Financial University under the Government of the Russian \\ Federation \\ Moscow, Russia \\ E-mail: ooipot@yandex.ru
}

\author{
Natalya Soldatova \\ Financial University under the Government of the Russian \\ Federation \\ Moscow, Russia \\ E-mail: ooipot@yandex.ru
}

\begin{abstract}
The paper is devoted to the issue of managing the human capacity at higher education institutions, namely the introduction of a new payment system and the shift towards effective contract of teaching staff as a management technology. The paper substantiates the significance of motivating professors to work effectively, to develop the professional competence and to achieve scientific results. The main attention is paid to the materials published by the Ministry of Education and Science of the Russian Federation oriented to the importance of the work-performance index, scientific publications, citation index, activity in the education sector, etc.
\end{abstract}

Keywords-management; university; human capacity; personnel policy; teaching quality evaluation; investments; development program

\section{INTRODUCTION}

For the last two decades there has been a noticeable growth in the importance of significance and importance of education as a socio-economic component of a nation's heritage, which is in the limelight of any civilized state. To enhance innovations and investments in education has become one of the main priorities of a long-term strategy of the socio-economic policy in the modern digital society. The aspect has both personal and social characteristics. Being one of the main means of acquiring knowledge and developing intellectual skills, education permits to actively participate in political, economic and cultural life of the global society. This provides society, as well as a whole nation, with an opportunity to affirm its intellectual and political independence, to take part in international life, particularly in conservation, enrichment and dissemination of world and national culture.

At present the issue of a person's education and intellectual development is becoming central, including the matter of investments in human resources.

We can highlight some of the Russian authors whose works are devoted to the problem of personnel management and increasing the education system efficiency by means of investments: Romanova Y.A., Egorenko A.O., Arutyunyan S.A., Bakuleva S.E., Borisevich M.A., Kotchetkova N.N.,
Metelitsa N.G., Popova E.A., Preina O.A., Solovtsova M.S., Slobodnyak I.A., Taimazova V.A., Shtanko E.Y., Schennikova M.Y. and others.

\section{ASPECTS OF PERSONNEL MANAGEMENT IN AN EDUCATIONAL INSTITUTION}

For the last two decades the system of education in Russia has undergone changes, reformation and transformation. We can outline the following new features of education:

- Foundation of various types of educational institutions (state and non-state);

- Forming of a non-state educational sector and development of business education;

- Replacement of standardized curricula with varied educational programs, which comprise federal, regional and local components;

- Forming and development of market mechanisms of management and sources of financing of educational institutions;

- A gradual transition to a multi-level system of a high-quality level staff training.

Organizational changes are aimed at raising management effectiveness and, as a rule, are connected with reforming of business strategy, e.g. penetrating new markets, merging and takeover of other companies, which is typical of the Russian business at its present stage of development. A modern organization functions under indefinite conditions: unexpected events occur quite quickly and organizations have to react fast and on time. Changes in an organization can be characterized as a deliberate action of the management taken in reference to the internal variables in this organization, defining its goals, structure, technology and human resources. The key factors of accelerating changes are as follows: buyers that are more demanding, globalization, technology, other non-information technology, organizations' responsibility, and employees. The listed factors form an unstable and unpredictable environment 
denoting that organizations are in the process of incessant changes. Even if an organization is on the rise and developing successfully, it is necessary to introduce some changes in its activity in order to preserve the leading position on its sectoral-product market. Thus, the process of organizational changes is, in fact, constant and serves as one of the most important objects of management [1].

Higher education personnel management is a complex function and during the process of forming and development presupposes direct funding into academic staff potential. Investments are aimed at raising the staff's professional skills and qualifications, hence the quality of the educational service provided by a university and required by the labor market.

Higher education human resources is a composition of skills and possibilities of academic staff and other employees of a university that are implemented for achieving current and perspective goals in favor of scientific and educational process.

To practice personnel administration, university staff management the professional development of it should not be the main objective. It must be tightly linked to the content and the level of labor required by a particular position, job families, and a university as a whole.

Human resource management must include the following complex functions of administration: identification of labor potential of a university, formal assessment of academic staff, defining the professional level of the academic staff and possibilities of its enhancement, management of the movement of personnel (career growth), forming of personnel reserve.

Functions of labor potential represents its abilities to meet the needs of a personality and a university. On the part of an organization this ability is conditioned by division of labor and specialization, and on the part of an employee - by professionalism. The basic functions of labor potential are production, stabilization, transformation, communication, stratification, translation and synthesis [2].

As for the development of human resources, it is important to emphasize such a function of management as assessment of an employee's potential, i.e. assessment of professional development and career promotion of an employee or his or her enrollment to the reserve. To do this, it is necessary to outline employee's sphere of interests, to discover career preferences, to define the degree of employee's correspondence to the projected position, to state the need in education. The assessment of the labor potential of an employee must be implemented in accordance with the projected changes in an organization or it must be based on forecasts of changes in personnel requirements.

Therefore, personnel management in an organization through the labor potential assessment presupposes addressing the following challenges:

- To form productive capacity of an employee which would to the fullest correspond with their work responsibilities at a new workplace;
- To create socio-economic and productive working conditions which would fully take advantage of employee's skills.

The most important condition of a successful development of personnel potential is a professional development of human resources that constitute a complex and continuous process of a comprehensive development of an employee's personality with the purpose of raising their work effectiveness.

\section{THE ROLE AND NECESSITY OF INVESTMENTS IN EDUCATION WITH THE PURPOSE OF MAINTAINING A SUSTAINABLE GROWTH OF THE NATIONAL ECONOMY}

Professional development is a process of preparing an employee for completing new production functions, occupying new positions, solving new tasks and which is aimed at overcoming divergence between the employee requirements and the qualities of a real person.

Among the events aimed at professional development of staff are a system of personnel skills development activities, teaching and scientific seminars within one department and between several departments, demonstration lessons by the leading professors and young specialists with a further detailed analysis, young teachers' school, studying English and other foreign languages, etc [4].

The most important tool of a professional development is a professional education. This is a process of direct transfer of new professional skills or knowledge of teachers. The above-mentioned young teachers' school and demonstration lessons can serve an example. The choice of forms and methods of education depend on whether an organization possesses financial and time resources. The right management of staff career development is a highly important task which is the responsibility of both personnel management service and the heads of all levels.

Owing to scientific theoretical research works and global experience, we can conclude that at the current stage the economic growth largely depends on the pace and scope of development of basic directions of scientific and technological progress, as well as the degree of progressiveness of scientific and productive means of labor and their results [5].

The most significant directions are research development and experimental and project-related development. These are responsible for economic growth and increase in the quality of education and educational system in general.

Therefore, the system of education must prepare not only highly qualified specialists but also scientists of a high level in accordance with the requirements of the new generation of knowledge and innovations. This, of course, calls for particular investments. On the other hand, however, the result will be forthcoming as this affects an increase in work efficiency and national income [6].

If we look at foreign experience, we can note the correlation between the contribution from scientific and technological achievements, introduction of organizational 
and technological changes, and a sustainable economic growth in the developed countries, which accounts for $40 \%$ of annual increase in national output. This serves as evidence that improvement of the higher education system on the base of investments and innovation give a noticeable contribution into the development of scientific and technological advances by its achievements and results gained due to graduating of highly qualified specialists.

Foreign countries, which are ahead of others by the level and pace of the development of scientific and technological advances and introduction of organizational and technological changes, acquire highly competitive advantages in the long term. This can be explained by the factors give below [7]

Firstly, investments in educational activity raise the level of professionalism and quality of the labor potential, let identify and develop creative skills of a person, raise the social status and to the full extent unleash intellectual and spiritual potential of society as a whole.

Secondly, although investments are more often implemented either in the short term in stages, or in a lump sum, payback comes in the long term. The longer the term, the more significant the results which will also be long-term. Nevertheless, there comes a moment when investors help is necessary to continue scientific research and to implement hands-on projects which definitely presupposes increase in qualification and re-training of staff potential in accordance with the changed conditions and the requirements of innovative renovation of production.

Consequently, we can conclude that investments in scientific and educational sphere bear a systematic form of turnover compared with the turnover of the major capital. However, it must be emphasized that both major and human resources potential in the period of investment increase their level and create a more qualitative service of a higher cost if compared with the staff of a previous level of training [8].

Thirdly, by all means, there is a time factor. The duration of the payback period must not exceed the period of skill obsolescence. This will lead to a decrease in the level of professionalism and lagging behind the knowledge in the relevant spheres and directions of scientific and technological advances. At the same time, the period of payback must not be too shortened as on the one hand, this can lead to a high cost of a delivered educational service. While on the other hand, a swift passage to new conditions of adaptation to implementing technological changes can result in moral and psychological pressure on personnel potential of professors, which in its turn can have negative consequences for an educational institution, such as low quality of educational activity and preventing the growth of qualification and professional development among academic staff.

Lastly, investments in education are aimed not only at forming new and at development of existing objects and subjects of education, material and technological support of educational institutions but also at improving learning process, developing new and enhancing current technologies, improving the training and re-training process of the whole personnel resources, including the management board and administrative personnel of a higher education establishment.

On the whole, we can point out the fact that the correspondence of educational process and personnel resources training in an educational institution to the modern requirements, global standards and trends dictates the necessity and the importance of investments in the development and improvement of the system of knowledge of scientific society, in fundamental and applied research works, raising social protection of academic staff in within the introduction of organizational changes and a shift to digital economy. Everything which was previously described allows scientific knowledge to be more accessible which, in its turn, helps to achieve a better efficiency from investments from specialists of a higher level during realization of investment-innovative projects.

\section{CONCLUSION}

To conclude, professional development and selfimprovement of academic staff and administrative employees in educational establishments is an investment program of education and career development. Its goal is to help to uncover employees' abilities and to use them properly in the innovative activity of an organization during the introduction of changes and transition to digital technologies, as the aim of managing academic staff development is to coordinate the interests of each employee and organization in the direction of accumulation and usage of human resources.

Investing in raising the qualitative level and professionalism of personnel potential influences a sustainable growth of a national economy, economic security and independence. For the last 20 years there has been studied a big number of theoretical sources and analytical data which permit to substantiate and prove the existence of a direct connection and correlation between investments in science and education as well as a sustainable economic growth taking into account the fact that a lion's share of investments has to be spent on development and improvement of higher education.

\section{REFERENCES}

[1] Yulia Romanova, Anna Egorenko Scientific Methodological Approach to Effective Contract Assessment. Advances in Social Science, Education and Humanities Research. Proceedings of the 2017 International Conference on Culture, Education and Financial Development of Modern Society (ICCESE 2017) Copyright (C 2017, the Authors. Published by Atlantis Press. This is an open access article under the CC BY-NC license Publication date May 2017 ISBN 978-94-6252-330-2 ISSN 2352-5398 doi:10.2991/iccese-17.2017.24 See for details: https://creativecommons.org/licenses/bync/4.0/ http://www.atlantispress.com/php/pub.php?publication=iccese-17

[2] Metelitsa N.G., Development of conceptual provisions of selfmanagement system of the teacher of a higher educational institution. Problems of modern science. 2017. No.28, pp. 61-69.

[3] Schennikova M.Yu., Bakulev S.E., Taymazov V.A., Borisevich M.A., The assessment of work efficiency of the teaching staff as a tool for 
task management. Scientific notes of the University. P. F. Lesgaft. 2017. № 4 (146). pp. 264-270.

[4] Slobodnyak I.A., Preina O.A., Assessment of the effectiveness of the teacher. Economics and management: problems, solutions. 2015. № 4. pp. 36-50.

[5] Arutyunyan S.A., Kochetkova N.N., Methodological aspect of the assessment of the effectiveness of the teaching staff of the University. Competitiveness in the global world: economics, science, technology. 2017. № 6-2 (50). pp. 10-14.

[6] World University Rankings 2016-2017 / Times Higher Education. https://www.timeshighereducation.com/world-universityrankings/2017/worldranking\#!/page/0/length/25/sort_by/rank/sort_order/asc/cols/stats. [45]

[7] World University Rankings 2016-2017 / Times Higher Education. https://www.timeshighereducation.com/world-universityrankings/2017/worldranking\#!/page/0/length/25/sort_by/rank/sort_order/asc/cols/stats. [47]

[8] TIMSS - Trends in Mathematics and Science Study, International study on the evaluation of the quality of mathematical and natural science education, conducted by an international educational center IEA's TIMSS \&PIRLS (Boston, CШA). TIMSS 2015 International Results Report / TIMSS \& PIRLS International Study Center. - 2015. results/download-center/. 